Chapter 3

\title{
A Comparative Study of Piperidinium and Imidazolium Based Ionic Liquids: Thermal, Spectroscopic and Theoretical Studies
}

\author{
Madhulata Shukla and Satyen Saha \\ Additional information is available at the end of the chapter \\ http://dx.doi.org/10.5772/51797
}

\section{Introduction}

Ionic liquids (ILs) comprise an extremely broad class of molten salts that are attractive for many practical applications because of their useful combinations of properties [1-3]. The ability to mix and match the cationic and anionic constituents of ILs and functionalize their side chains. These allow amazing tenability of IL properties, including conductivity, viscosity, solubility of diverse solutes and miscibility/ immiscibility with a wide range of solvents. [4] Over the past several years, room temperature ILs (RTILs) has generated considerable excitement, as they consist entirely of ions, yet in liquid state and possess minimal vapour pressure. Consequently, ILs can be recycled, thus making synthetic processes less expensive and potentially more efficient and environmentally friendly. Considerable progress has been made using ILs as solvents in the areas of monophasic and biphasic catalysis (homogeneus and heterogeneous).[5-6] The ILs investigated herein provides real practical advantages over earlier molten salt (high temperature) systems because of their relative insensitivity to air and water. [6-7] A great deal of progress has been made during last five years towards identifying the factors that cause these salts to have low melting points and other useful properties.[8] ILs are subject of intense current interest within the physical chemistry community as well. There have been quite a lot of photophysical studies in ionic liquids. [8] The most important properties of ionic liquids are: thermal stability, low vapour pressure, electric conductivity, liquid crystal structures, high electro-elasticity, high heat capacity and inflammability properties enable the use of ionic liquids in a wide range of applications, as shown in Figure 1. It is also a suitable solvent for synthesis, [5, 8, 9-12] catalysis [6, 8, 13] and purification. [14-18] It is also used in electrochemical devices and processes, such as rechargeable lithium batteries and electrochemical capacitors, etc.[19] Rechargeable Lithium 
batteries are a ubiquitous energy device that is being worldwide in many types of portable electronic equipment, such as cellular phones, laptop computers, and digital cameras and many more devices.[20] Recently, it has been realized that variation of the type of cationic core is a very valuable approach to get more number of ILs.[8]

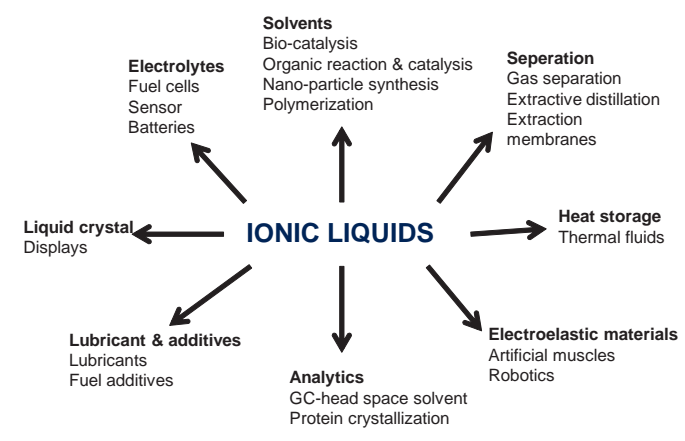

Figure 1. Applications of Ionic Liquids

A major difference between imidazolium salt on one hand and piperidinium salts on the other hand is that the positive charge is delocalized over the aromatic ring in imidazolium salt, whereas the positive charge is localized on the nitrogen atom of piperidinium salts. Next to imidazolium, piperidinium based ILs are the most popular and versatile. Several literatures are available on study of imidazolium based ILs, where x-ray crystallography studies [21-22], theory [23-28], viscosity [8], spectroscopic studies including IR and Raman spectra [27] have been discussed. In comparison to this, very few literatures exist related to piperidinium based ILs. During the last five years interest towards piperidinium based ILs has increased considerably. Cyclic alkyl quaternary ammonium (QA) cations, N-alkyl-Nmethylpiperidinium ( $\mathrm{PIP}_{1 \mathrm{n}}$; where 1 indicates $\mathrm{CH}_{3}$ and $\mathrm{n}=$ number of carbon in another alkyl substitution) are class of cations whose room temperature ILs (RTILs) are very promising in the field of electrochemical applications due to their high thermal and electrochemical stabilities.[29-43] Recently, PIP $_{1 n}$ ILs found to be potentially useful for electrochemical applications due to their water immiscibility, high conductivities, thermal stabilities and wide electrochemical windows. For example, 1-butyl-1-mehylpiperidinium bis(trifluoromethylsulfonyl)imide ( $\mathrm{PIP}_{14} \mathrm{NTf}_{2}$; where, $\mathrm{NTf}_{2}:$ : bis(trifluoromethylsulfonyl)imide anion) improves the stabilization of the chemical composition and structure of the sulphur cathode in $\mathrm{Li} / \mathrm{S}$ cells during charge-discharge cycles. In the state of the art technologies of $4 \mathrm{~V}$-class rechargeable Li batteries, a mixture of organic aprotic solvents and LiPF6 is generally used.[44] Recent studies have shown that the highly fluid and conductive 1, 3-dialkylimidazolium salts cannot be used as electrolyte for $4 \mathrm{~V}$-class $\mathrm{Li}$ batteries, because of very positive cathodic potential of the 1,3-dialkylimidazolium cations. [45-47] On the other hand, it was revealed that the ILs based on quaternary ammonium cations with the electrochemically stable and weak- 
ly coordinating anion, $\mathrm{NTf}_{2}^{-}$offer some promising properties.[48-50] These promising properties mainly include i) wide electrochemical windows on account of the low cathodic potential of the saturated QA cations and the high anodic potential of the $\mathrm{NTf}_{2}{ }^{-}$, ii) low viscosities on account of the high flexibility and good charge distribution of the $\mathrm{NTf}_{2}{ }^{-}$, and iii) wide stable liquid ranges on account of the low melting point and high thermal stability of the $\mathrm{NTf}_{2}{ }^{-}$salts.[51-54] The free $\mathrm{NTf}_{2}$ anion itself has several interesting features.[55] The negative charge can be expected to delocalized over five atoms (four oxygen and the nitrogen), implicating a weak coordinating power. This is of vital importance in the applications where the formation of ion pairs would reduce the number of charge carriers and hence the ionic conductivity. The possibility of rotations around the two central S-N bonds would provide a mechanical flexibility resulting in a plasticizing effect of the polymer electrolyte, making the system more conductive due to the large internal mobility of the dissolved species. Both these effects have been observed for polymer electrolytes based on PEO/LiNTf 2 [56-57] and PEO/alkaline salts.[58] As for example, $\mathrm{PIP}_{1 n} \mathrm{NTf}_{2}$, have been recently proposed for highvoltage super capacitors and lithium batteries.[31-33, 36] Particularly $\mathrm{PIP}_{13} \mathrm{NTf}_{2}$ has been found to be useful for the use in Li-batteries [38] with a superior reversible discharge capacity of 340-350 mA-h/g with only a small irreversible capacity loss per cycle [59]. Despite this tremendous interest, the properties, molecular structure and theoretical calculation of $\mathrm{PIP}_{1 \mathrm{n}}$ cation based ILs have not been investigated in detail so far. As the properties of any material depends on the structure of molecules in different phases, it is important to understand the structural features of ILs in depth. In general, liquids are much less understood than gases and crystals. While structure in the gas phase can be accurately determined by electron diffraction or high-resolution rotationally-resolved spectroscopy, solid/crystal structure can be determined by X-ray or neutron diffraction. On the other hand, diffraction and spectroscopic techniques has limited applicability to elucidate liquids structure. Structural information available for liquids is thus much less. Thus theoretical calculations are of very much important in predicting the structure of different room temperature ionic liquids (RTILs). In particular, Density Functional Theory (DFT) calculation found to be very useful in predicting structure of various RTILs. [23-24, 27] DFT calculation also helps us to understand the interaction present among cation and anion in the molecule as well as the type of bonding present in the molecule. Magnetic moment, dipole moment and many other physical properties as well as wavelength of various electronic transition of ILs can also be calculated by DFT calculation. In this chapter we addressed the following very specific issues related to important class of piperidinium based ILs. Synthetic procedure for different piperidinium based ILs has been described and it was found that with variation of anion, cation being the same, physical state of ILs changes drastically.[23] Thermophysical properties of imidazolium and piperidinium based cation with similar anion has been compared briefly. Melting point, viscosity and cyclic voltammetry properties with variation of alkyl chain as well as variation of several anions has been reported for both types of cation. Further we have compared the optimized molecular geometry of bmimBr, bmimI and bmimNTf2 ion pairs with $\mathrm{PIP}_{14} \mathrm{Br}, \mathrm{PIP}_{14} \mathrm{I}$ and $\mathrm{PIP}_{14} \mathrm{NTf}_{2}$ respectively in gaseous phase using theoretical calculations. bmimBr and bmimI ILs, exist as solid of very low melting point or in liquid state [22], whereas its analogous piperidinium based ILs (PIP ${ }_{14} \mathrm{Br}$ and $\mathrm{PIP}_{14} \mathrm{I}$ respectively) exist in solid 
having high melting point. In addition, the calculated vibrational frequency of the molecule gives us a strong base to analyze the experimental spectra and also the effect of interaction causing shifting in vibrational bands. Further, experimental IR frequencies of $\mathrm{PIP}_{14} \mathrm{NTf}_{2}$ and its correlation with theoretical (DFT and HF methods) vibrational frequencies have been reported.

\section{Reagents and instrumentation}

N-methylpiperidine (Sigma Aldrich, >99\%), bromobutane, Iodobutane (Merck, Germany), bis(trifluoromethanesulfonyl)imide (Sigma Aldrich, $>99 \%$ ) were used as received for the synthesis. Acetonitrile (HPLC grade) was procured from Merck, Germany and were used after purification following standard procedures. UV-Visible spectra were measured by CARY 100 BIO UV- Visible Spectrophotometer, which has photometric linearity till absorbance 3.5. Infrared spectra were was measured with Varian FTIR 3100 in the region $400 \mathrm{~cm}^{-1}-3500$ $\mathrm{cm}^{-1}$ using neat sample. $300 \mathrm{MHz}$ NMR (JEOL) was used to measure the ${ }^{1} \mathrm{H}$ NMR and ${ }^{13} \mathrm{C}$ NMR. Melting point of the synthesized samples were recorded using automatic digital melting point apparatus (Optimelt).

\section{Experimental}

\subsection{Conventional preparation for ammonium cation based ILs}

The general synthetic path for preparing ammonium based ILs is shown in Figure 2. The first step usually is a quaternization reaction, where an amine $\left(\mathrm{NR}_{3}\right)$ is alkylated with an appropriate alkylation reagent $\left(\mathrm{R}^{\prime} \mathrm{X}\right)$ e.g. alkyl halide, resulting in the corresponding IL. When an IL with a desired anion cannot be formed via this reaction, an anion exchange reaction is needed. A previously formed IL is used as precursor and the anion is changed by a metathesis reaction. This metathesis reaction can be performed by using a metal salt (MA).

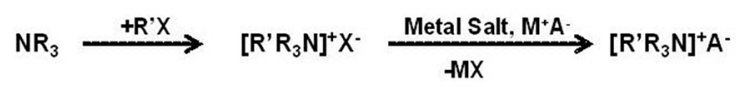

Figure 2. Synthetic path for preparing ammonium based ILs

3.2. Synthesis of 1-butyl-3-methylimidazolium halide (bmim $X$, where $\mathrm{X}^{-}=\mathrm{Br}$, I) and bmimNTf $_{2}$

Synthetic Procedure for bmim X and bmimNTf $f_{2}$ have been reported by us earlier [24] Since we have used considerable less temperature than generally reported [60], the time required 
for the reactions are also much higher. Nevertheless, this low temperature reaction has been found to provide much purer ILs.

\subsection{Synthesis of N-butyl-N-methylpiperidinium halide $\left(\mathrm{PIP}_{1 \mathrm{n}} \mathrm{X}\right.$, where $\left.\mathrm{X}^{-}=\mathrm{Br}, \mathrm{I}\right)$ and PIP $_{14}$ NTf $_{2}$}

\subsubsection{Synthesis of $N$-butyl-N-methylpiperidinium bromide $\left(P I P_{14} B r\right)$}

A general synthesis procedure for synthesizing $\mathrm{PIP}_{14} \mathrm{Br}$ was reported in literature.[40] $\mathrm{A}$ modified form of that reported procedure is followed; instead of using high temperature, lower temperature $\left(50{ }^{\circ} \mathrm{C}\right)$ is used with longer time of stirring. This excludes major possibilities of inclusion of impurities in ionic liquids. Scheme for the synthesis of $\mathrm{PIP}_{14} \mathrm{Br}$ is shown in Figure 3. $20 \mathrm{~mL}$ of ethyl acetate was taken in $100 \mathrm{~mL}$ RB flask. To it $10 \mathrm{~mL}$ (82.3 mmol) Nmethyl piperidine was added with stirring and then $9.7 \mathrm{~mL}(90.5 \mathrm{mmol})$ of bromobutane was added slowly with continuous stirring at $25{ }^{\circ} \mathrm{C}$. Mixture was stirred for $16 \mathrm{~h}$ at RT in nitrogen atmosphere and then stirring was made at $50{ }^{\circ} \mathrm{C}$ for $3 \mathrm{~h}$. The solution was washed with $150 \mathrm{~mL}$ dry distilled ethylacetate and remaining solvent was evaporated on a rotavapour. White solid product was kept under high vaccum at $50{ }^{\circ} \mathrm{C}$ for $3 \mathrm{~h}$. (yield $=90 \%$ ). Melting point (mp) found to be $241^{\circ} \mathrm{C}$. The product was confirmed by ${ }^{1} \mathrm{H} N M R(\delta, p p m, 1.01(\mathrm{t}$, $3 \mathrm{H}), 1.47(\mathrm{q}, 2 \mathrm{H}), 1.72(8 \mathrm{H}), 3.63(\mathrm{~s}, 3 \mathrm{H}), 3.66(4 \mathrm{H})$ and $3.81(2 \mathrm{H})$; IR: 569, 673, 904, 940, 1030, $1227,1369,1464,2874$ and $2959 \mathrm{~cm}^{-1}$.

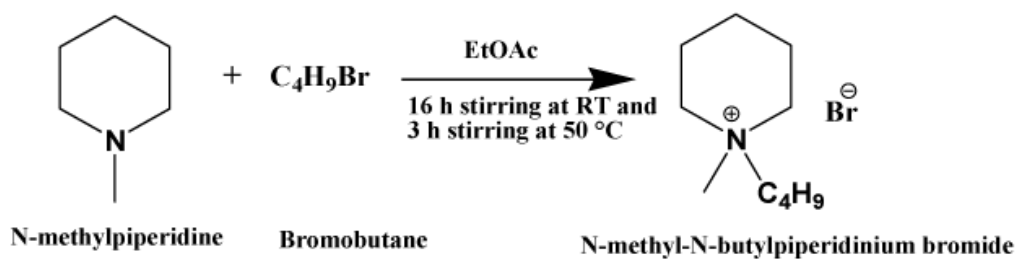

Figure 3. Scheme for the synthesis of $\mathrm{PIP}_{14} \mathrm{Br}$

\subsubsection{Synthesis of N-alkyl-N-methylpiperidinium Iodide $\left(P I P_{1 n} I\right)$}

A general synthesis procedure for synthesising $\mathrm{PIP}_{1 \mathrm{n}} \mathrm{I}$ (where $\mathrm{n}=1,3,4,6,8$ ) is shown in Figure 4 . As above mentioned process, here also instead of using high temperature, RT is preferred with longer time of stirring to exclude the major possibilities of inclusion of impurities in ionic liquids. All the reactions were carried out with 1:1.1 molar ratios. $10 \mathrm{~mL}$ of Ethyl acetate was taken in $100 \mathrm{~mL}$ RB flask. To it $2 \mathrm{~mL}$ (16 mmol) N-methyl piperidine was added with stirring and then $\mathrm{X} \mathrm{mL}(\mathrm{X} \mathrm{mmol})$ of iodoalkane was added slowly with continuous stirring at $25{ }^{\circ} \mathrm{C}$. Mixture was stirred for $24-48 \mathrm{~h}$ at RT in nitrogen atmosphere (except for $\mathrm{PIP}_{11} \mathrm{I}$, where stirring was done for $4 \mathrm{~h}$ only). The solution was washed with $150 \mathrm{~mL}$ dry distilled ethylacetate and remaining solvent was evaporated on a rotavapour. White solid product was kept under high vacuum for $3 \mathrm{~h}$. Yield for $\mathrm{PIP}_{11} \mathrm{I}=100 \%$ and for rest of the 
salt, it is found to $70 \%$. Melting point (mp) found to be $181^{\circ} \mathrm{C}, 198^{\circ} \mathrm{C}, 124^{\circ} \mathrm{C}$ and $131^{\circ} \mathrm{C}$ for $\mathrm{PIP}_{13} \mathrm{I}, \mathrm{PIP}_{14} \mathrm{I}, \mathrm{PIP}_{16} \mathrm{I}$ and $\mathrm{PIP}_{18} \mathrm{I}$ respectively. The products were confirmed by ${ }^{1} \mathrm{H} \mathrm{NMR},{ }^{13} \mathrm{C}$ NMR and IR.

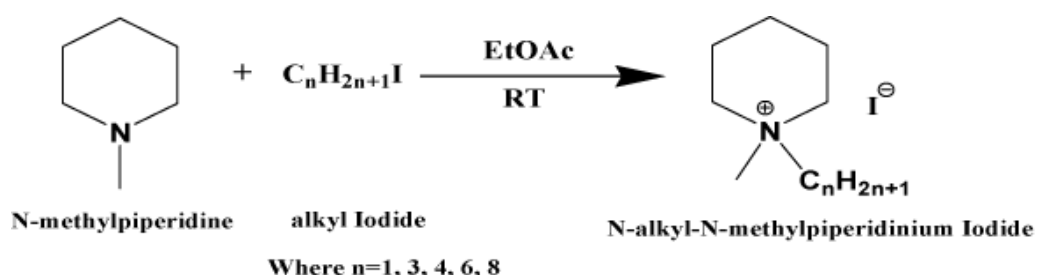

Figure 4. Scheme for the synthesis of $\mathrm{PIP}_{1 \mathrm{n}} \mathrm{I}$

\subsubsection{Synthesis of $N$-butyl-N-methylpiperidiniumbis(trifluoromethanesulfonyl)imide $\left(P I P_{14} N T f_{2}\right)$}

$\mathrm{PIP}_{14} \mathrm{NTf}_{2}$ was done following the similar procedure as described in literarture.[40] Scheme for preparation of $\mathrm{PIP}_{14} \mathrm{NTf}_{2}$ is shown in Figure 5.4.6 g (19.5 mmole) of $\mathrm{PIP}_{14} \mathrm{Br}$ was taken in a $\mathrm{RB}$ and to it $10 \mathrm{~mL}$ of triple distilled (TD) water was added. $6.1 \mathrm{~g}(21.4 \mathrm{mmole}) \mathrm{LiNTf}_{2}$ dissolved in $10 \mathrm{~mL}$ TD water added to it. Stirring was done for $4 \mathrm{~h} .150 \mathrm{~mL}$ dichloromethane (DCM) solvent was used to wash followed by the cold distilled water. DCM was evaporated on rotavapour and after that it was kept under high vaccum for $2 \mathrm{~h}$ at $60^{\circ} \mathrm{C}$. Light yellow colour liquid was obtained with a yield of $88 \%$. This light yellow colored liquid was further dissolved in $10 \mathrm{~mL}$ of pure predistilled acetonitrile $(\mathrm{ACN})$ and treated with activated celite for decolorization. Room temperature stirring was done for $4 \mathrm{~h}$ followed by filtration through a column packed with fresh charcoal and activated alumina. The resultant solution was evaporated on rotavapour at reduced pressure. Completely colorless liquid was obtained. The product was confirmed by ${ }^{1} \mathrm{H} N M R(\delta, p p m, 1.01$ $(\mathrm{t}, 3 \mathrm{H}), 1.44(\mathrm{q}, 2 \mathrm{H}), 1.74(8 \mathrm{H}), 3.42(\mathrm{~s}, 3 \mathrm{H}), 3.56(4 \mathrm{H})$ and $3.85(2 \mathrm{H})$ and IR: 570, 619, 1054, 1139, $1197,1348,1474,2881$ and $2966 \mathrm{~cm}^{-1}$.

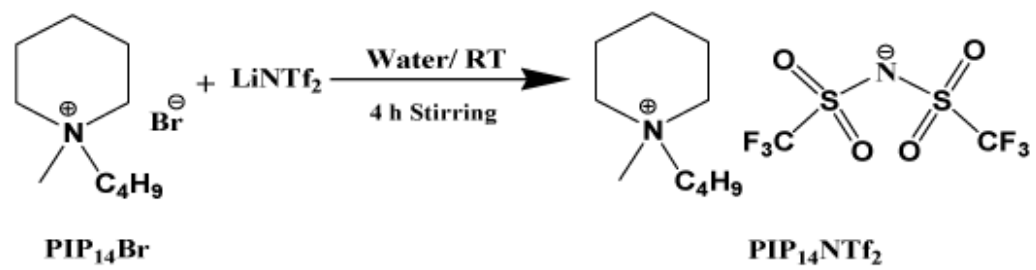

White solid

Colorless liquid

Figure 5. Scheme for the synthesis of $\mathrm{PIP}_{14} \mathrm{NTf}_{2}$ 


\section{Thermo-physical properties study}

The thermal stability of an ionic liquid is determined by the strength of the formed heteroatom-carbon or heteroatom-hydrogen bonds and the stability of the formed ion species. Although there have been extensive studies of RTILs, relations between their structure and physicochemical properties has not yet been fully understood. The primary research on the properties of pure ILs has focused on understanding and developing the relationship between the structures of cation and anion and the physical properties. To optimize the use of ILs and design the desirable ILs, knowledge of physical and chemical properties of ILs is essentially important. Physical properties such as melting point, viscosity, glass transition temperature, density, surface tension etc. must be known before utilizing them as either green solvent for chemical reactions or for the usage as new materials for various applications.[61] In addition, basic thermodynamic properties are also vital for design and evaluation of its application.

The melting point $\left(\mathrm{T}_{\mathrm{m}}\right)$ of an organic molecular compound is determined by the strength of its crystal lattice, which is in turn controlled by three main factors: molecular symmetry, intermolecular forces, and conformational degrees of freedom of the molecule. This principle is also applicable to the ILs, as intensively described in a very large number of well-characterized imidazolium and QA salts [62-63]. For ILs, melting points is one of the most important physical properties and have been studied with interest. The melting point primarily indicates whether a salt should be considered as IL or not. The melting point of an ionic liquid depends on its cation/anion composition [61]. Generally, symmetric ions with a localized charge and strong interactions between ions result in good packing efficiency and hence a high melting point (e.g. $\mathrm{mp}$ of $\mathrm{NaCl}: 801^{\circ} \mathrm{C}$ ) [64]. Ionic liquids based on large, asymmetric cations with a delocalized charge often have low melting points. Packing efficiency depends on interactions between ions. Hydrogen bonding (or similar non-bonded interactions) increases the order of the system and thus raises the melting point [65].The relations between density with melting temperature, along with glass transition decomposition temperature and heat capacities for a series of imidazolium based ILs have been reported [66-68]. A series of hydrophilic and hydrophobic 1-alkyl-3-methylimidazolium and 1-alkyl-1-methylpiperidinium salts of $\mathrm{NTf}_{2}^{-}, \mathrm{PF}_{6}^{-}, \mathrm{BF}_{4}^{-}, \mathrm{Br}^{-}$and $\mathrm{I}^{-}$has been presented in Table 1 . Data presented in Table 1 shows that most of the imidazolium based ILs found to exist in liquid at room temperature or having low melting point. In comparision to this, piperidinium based ILs have very high melting behaviour. Melting points reported here clearly shows that for a different cation, anion being same piperidinium based ILs found to have quite higher than those of imidazolium based ILs. As for example, melting point of bmimBr $\left(79^{\circ} \mathrm{C}\right)$, hmimBr $\left(-54.9^{\circ} \mathrm{C}\right)$ are quite low as compared to its corresponding $\mathrm{PIP}_{14} \mathrm{Br}\left(241^{\circ} \mathrm{C}\right)$ and $\mathrm{PIP}_{16} \mathrm{Br}\left(201^{\circ} \mathrm{C}\right)$ salts. Similarly for bmimI $\left(-72^{\circ} \mathrm{C}\right)$ and hmimI $\left(-72^{\circ} \mathrm{C}\right)$, compared with $\mathrm{PIP}_{14} \mathrm{I}$ $\left(198^{\circ} \mathrm{C}\right)$ and $\mathrm{PIP}_{16} \mathrm{I}\left(124^{\circ} \mathrm{C}\right)$ have quite high difference in melting point value. Compared to bmimBF $4\left(-81^{\circ} \mathrm{C}\right)$, corresponding $\mathrm{PIP}_{14} \mathrm{BF}_{4}\left(146^{\circ} \mathrm{C}\right)$ salt have huge difference in melting point. This significant difference in melting point behaviour is expected due to molecular interaction present between cation and anion, which has been discussed further in following sections. Melting point of $\mathrm{PIP}_{14} \mathrm{NTf}_{2}$ as well as bmimNTf $f_{2}$ reported to be $-25^{\circ} \mathrm{C}$ [30-32]. It is 
interesting to note that when anion is larger with having multiple interacting sites (such as $\mathrm{NTf}_{2}$ ), the difference of $\mathrm{mp}$ between piperidinium and imidazlium cation based ILs fades away. Therefore, one can have two drastically different types of ILs having same mp.

\begin{tabular}{|c|c|c|c|c|c|}
\hline Imidazolium ILs & $\begin{array}{l}\text { Melting point } \\
\left(t_{m}{ }^{\circ} \mathrm{C}\right)[\text { ref] }\end{array}$ & Viscosity (n)/ cP & Piperidinium ILs & $\begin{array}{c}\text { Melting point }\left(\mathrm{t}_{\mathrm{m}}{ }^{\circ} \mathrm{C}\right) \\
\text { [ref] }\end{array}$ & Viscosity (n)/ cP \\
\hline bmimBr & $79[22]$ & solid & $\mathrm{PIP}_{14} \mathrm{Br}$ & $241[40]$ & solid \\
\hline $\mathrm{hmimBr}$ & $-54.9[69]$ & 3986 & $\mathrm{PIP}_{16} \mathrm{Br}$ & $201 *$ & solid \\
\hline pmiml & $-56[70]$ & 35 & $\mathrm{PIP}_{13} \mathrm{I}$ & 181 * & solid \\
\hline bmiml & $-72[66]$ & $1110[66]$ & $\mathrm{PIP}_{14} \mathrm{I}$ & 198 * & solid \\
\hline hmiml & $-72[66]$ & 771 & $\mathrm{PIP}_{16} \mathrm{I}$ & 124 * & solid \\
\hline $\mathrm{bmimBF}_{4}$ & $-81[66]$ & $219[66]$ & $\mathrm{PIP}_{14} \mathrm{BF} 4$ & $146[40]$ & solid \\
\hline $\operatorname{bmimPF}_{6}$ & $4[66]$ & $450[66]$ & $\mathrm{PIP}_{14} \mathrm{PF}_{6}$ & - & solid \\
\hline $\mathrm{hmimPF}_{6}$ & $-61[66]$ & $585[66]$ & $\mathrm{PIP}_{16} \mathrm{PF}_{6}$ & 188.7 * & solid \\
\hline emimNTf $_{2}$ & $4[66]$ & $28[66]$ & $\mathrm{PIP}_{12} \mathrm{NTf}_{2}$ & $84.3[71]$ & solid \\
\hline bmimNTf $_{2}$ & $-25[66]$ & $69[66]$ & $\mathrm{PIP}_{14} \mathrm{NTf}_{2}$ & $-25[21,40]$ & $182[40]$ \\
\hline
\end{tabular}

* our results

Table 1. Melting point of some popular imidazolium and piperidinium cation based ILs.

\subsection{Viscosity}

The viscosity of an ionic liquid is a very important parameter in electrochemical studies due to its strong effect on the rate of mass transport within solution. The type of the anion and the cation which compose the ionic liquid have a huge effect on the viscosity of the ionic liquid. With respect to the anionic species, higher capacity and relative basicity to form hydrogen bonds result in more viscous RTILs. Viscosity of several imidazolium ILs has been presented in Table 1 but piperidinium based ILs (almost all of them except PIP $_{14} \mathrm{NTf}_{2}$ ) are solid at room temperature and hence their viscosity data are not available. Viscosity of bmimPF6 $(450 \mathrm{cP})$ found to nearly double when compared with viscosity of bmimBF$_{4}$ (219cP).[66] This may be due to presence of more number of hydrogen bonding present in bmimPF 6 , than bmimBF$_{4}$. Whereas, ionic liquids containing $\mathrm{BF}_{4}^{-}$anions are much more viscous than those formed with $\mathrm{NTf}_{2}^{-}$anions, where the negative charge is delocalized. An increase in the viscosity of the various anion/cation combinations was attributed to an increase in van der Waals forces over hydrogen bonding.[72] However, hydrogen bonding between cationic protons and anionic halides has been noted in the crystalline state from X-ray diffraction studies [73-74] and may represent an additional factor. In addition, the increased symmetry of the inorganic anions (e.g., $\mathrm{PF}_{6}^{-}$or $\mathrm{BF}_{4}^{-}$) compared to the organic anion $\left(\mathrm{NTf}_{2}^{-}\right)$ may play an important role. The data of Table 1 seems to indicate that the geometry and molar mass of the anions have a strong influence on the viscosity of this class of IL, since 
[bmim $]^{+}$combined with either $\mathrm{PF}_{6}^{-}$or $\mathrm{NTf}_{2}{ }^{-}$, produces ILs with significantly different viscosities. These results suggest a complex relationship of cation-anion interactions. ILs containing $\mathrm{NTf}_{2}$ anions are the most widely used for electrochemical applications due to their low viscosity and, consequently, improved mass transport. Viscosity of bmimNTf ${ }_{2}(62 \mathrm{cP})$ [66] found to be much lower than that of $\mathrm{PIP}_{14} \mathrm{NTf}_{2}(182 \mathrm{cP})$ [40]. Hence the viscosity of ILs is controlled by the number of hydrogen bonding between cation and anion, as well the van der Waals interaction. Hence bmimNTf ${ }_{2}$ seems to have wide application in electrochemistry as compared to $\mathrm{PIP}_{14} \mathrm{NTf}_{2}$.

\subsection{Cyclic voltammetry}

The ionic conductivity of an IL is another most important property, aiming its application as electrolyte for electrochemical devices. It is expected that ILs possesses a large conductivity, since they are composed exclusively by ions. However, in addition to the number of charge carriers, their mobility should also be taken into account. Cyclic Voltammogram of both ILs (bmimNTf $f_{2}$ and $\mathrm{PIP}_{14} \mathrm{NTf}_{2}$ ) using carbon glass electrode as working electrode and current density limit at $150 \mu \mathrm{A} \mathrm{cm} \mathrm{cm}^{-2}$ is shown in Figure 6. The utility of a liquid for electrochemical applications is frequently reflected in the width of the electrochemical windows (EW). The electrochemical window is defined as the potential range where the limiting current density is reached. EW for bmimNTf found to be only $3 \mathrm{~V}$, whereas EW for $\mathrm{PIP}_{14} \mathrm{NTf}_{2}$ found to be 4.5V i.e $\mathrm{PIP}_{14} \mathrm{NTf}_{2}$ has $1.5 \mathrm{~V}$ wider EW as compared to bmimNTf 2 . This $1.5 \mathrm{~V}$ advantage over the bmimNTf $f_{2}$ is due to the fact that the aromatic imidazolium core is much more readily reduced than the piperidnium system, which contain no vacant orbital as explained by Belhocine et al. for azepanium and 3-methylpiperidinium based ILs. [75] They have also shown that azepanium and 3-methylpiperidinium based ILs have higher EW as compared to imidazolium based ILs. Hence EW is one of the fundamental properties required for evaluating the ILs as electrolyte in many electrochemical devices. Hence this property of $\mathrm{PIP}_{14} \mathrm{NTf}_{2}$ leads to its extensive use in electrochemical processes. This is the most important advantages of piperidinium based ILs over imidazolium based ILs.

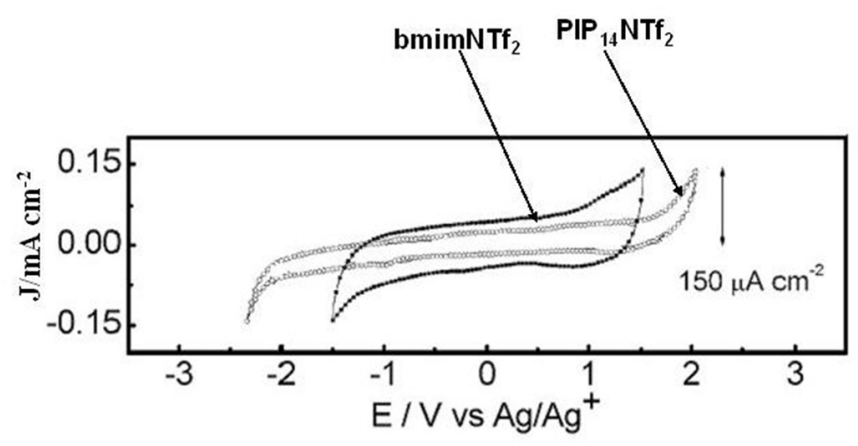

Figure 6. Cyclic Voltammogram of bmimNTf${ }_{2}(\bullet)$ and $\mathrm{PIP}_{14} \mathrm{NTf}_{2}(\mathrm{o})$ 


\section{Computational details}

\subsection{Studies of interactions in molecular structure of different ILs using DFT calculations}

Optimization of ion pairs was done using density functional theory (DFT), MP2 and Hartee-Fock (HF) methods to get the most stable structure. DFT computations were performed at Becke's three-parameter hybrid model using Lee-Yang-Parr correlation functional (B3LYP) level of theory. [76-77] 6-31++ G $(d, p)$ basis set used to get the optimized geometry and IR bands using Gaussian 03 programme.[78] IR frequencies calculations was performed using DFT and HF method [27], to compare which method produces better experimental results. All optimized structures were confirmed to be minimum energy conformation, as no imaginary frequencies are obtained.

Molecular geometry optimization of $\mathrm{PIP}_{14} \mathrm{X}$ and bmimX ion pairs carried out at B3LYP/6-31+ $+\mathrm{G}(\mathrm{d}, \mathrm{p})$ level in gaseous phase and has been shown in Figure 7. DGDZVP basis set was used for iodine atom, as explained in our previous paper. [23-24] The optimized structure reveals that piperidinium ring is stable in chair conformation and butyl group in trans conformation, as reported by Reichert et al. for PIP $_{1 n}$ I crystal.[42]. Hydrogen bonding present in these moieties is shown with the dotted line. H---Br distances in PIP14Br found to be $2.57 \AA$, $2.45 \AA$ and $2.54 \AA$ (shown in Figure 7a) which are smaller than van der Waal radius and also C17-H18----Br, C2-H6----Br and C22-H27---Br angle found to be $155^{\circ}, 153^{\circ}$ and $156^{\circ}$ respectively. C-H---Br bond length and angle presented in Table 2 satisfied the conditions of $\mathrm{H}$ bonding definition. Hence H-bonding present in piperidinium ILs or salts have strong control over the physical property of the moiety. When compared with 1-butyl-3-methylimidazolium bromide (bmimBr, $\mathrm{mp}=79{ }^{\circ} \mathrm{C}$ ) IL [22], its melting point found to be quite high $\left(241^{\circ} \mathrm{C}\right)$. This can be explained as, in bmimBr IL, only one $\mathrm{H}$-bonding is present between cation and anion (shown in Figure $7 \mathrm{~b}$ ) with $\mathrm{C} 2-\mathrm{H}---\mathrm{Br}$ distance of $2.19 \AA$ and $\mathrm{C} 2-\mathrm{H}---\mathrm{Br}$ bond angle of $154^{\circ}$. While in $\mathrm{PIP}_{14} \mathrm{Br}$ moiety, three H-bonding are observed with single $\mathrm{Br}$ - ion, leading to its higher melting point. In bmimBr, no $\mathrm{H}$ - bonding was observed between anion and alkyl chain, whereas in $\mathrm{PIP}_{14} \mathrm{Br}$ moiety, two H-bonding with alkyl chain along with one $\mathrm{H}$-bonding with hydrogen of piperidine ring was observed. Hence this higher number of $\mathrm{H}$ bonding present in $\mathrm{PIP}_{14} \mathrm{Br}$ led to its higher melting point. Similar is the reason for the higher melting point of $\mathrm{PIP}_{1 \mathrm{n}} \mathrm{I}$ salts, when compared to those of bmimI. In PIP ${ }_{14} \mathrm{I}, \mathrm{H}---\mathrm{I} \mathrm{H}$ bonding found to be 2.78, 2.86 and $2.98 \AA$, (shown in Figure 7c) whereas, in bmimI, single Hbonding of bond length $2.50 \AA$ exist between cation $(\mathrm{C} 2-\mathrm{H})$ and iodide anion (shown in Figure $7 \mathrm{~d}$ ). Here also three $\mathrm{H}$-bonding between cation and anion lead to its higher melting point when compared with bmimI. Theoretical calculation on NTf2 anion based ILs have attracted attention in recent times. Several literatures are available for bmimNTf $\mathrm{IL}_{2}$, where DFT calculation performed to explain the conformation of cation as well as anion. [79] According to Fujii et al., DFT calculation followed by frequency analyses confirms two conformations (cis and trans) of $\mathrm{NTf}_{2}{ }^{-}$anion with an energy difference of $2.2-3.3 \mathrm{~kJ} \mathrm{~mol}^{-1}$ and trans conformation reported to be more stable than the cis conformation. Keeping these stable conformations in mind, we further carried out theoretical calculation for $\mathrm{PIP}_{14} \mathrm{NTf}_{2}$ ion pair in gaseous phase. The selected structural parameters for $\mathrm{PIP}_{14} \mathrm{Br}$ and $\mathrm{PIP}_{14} \mathrm{NTf}_{2}$ are shown in 
Table 2. Optimized structure of $\mathrm{PIP}_{14} \mathrm{NTf}_{2}$ (shown in Figure 7e) explains three H-bonding of

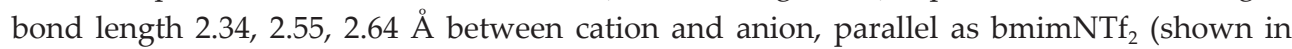
Figure 7f). Hence in case of $\mathrm{NTf}_{2}$ anionic ILs, melting point of both imidazolium and piperidinium based ILs found to be nearly comparable to each other. It is due to the fact that number of $\mathrm{H}$-bonding is same in both cases. Further, discussion on $\mathrm{PIP}_{14} \mathrm{NTf}_{2} \mathrm{IL}_{\text {has }}$ been done in detail, as it $\left(\mathrm{NTf}_{2}{ }^{-}\right.$based ILs) exist in liquid state at room temperature. From Table 2, it is clear that, N-S, S=O, S-C and C-F bond length calculated using DFT found to be 1.62, 1.46, 1.89 and $1.33 \AA$, which deviate by $0.05,0.04,0.07$ and $0.01 \AA$ from the crystal data reported in literature.[79] Whereas bond lengths calculated using HF method are in good agreement with those in the crystals, its bond angle and dihedral angles are largely different. On the other hand, bond length calculated at B3LYP level of theory are appreciably larger than those in crystal data, whereas the S-N-S bond angle, C-S-S-C and S-N-S-C dihedral angles are reproduced fairly well. Indeed MP2 calculation also produces similar result as DFT but its time consumption is nearly thrice of that of DFT method. Hence DFT proves to be the best among these three methods to reproduce the crystal data.

\begin{tabular}{|c|c|c|c|c|c|c|}
\hline Parameter & PIP14Br & $\begin{array}{c}\text { Parameter/ } \\
\text { PIP }_{14} \text { NTf }\end{array}$ & $\begin{array}{c}\text { crystal data } \\
\text { (reported) [79] }\end{array}$ & DFT results & MP2 results & HF results \\
\hline $\mathrm{H} 18-\mathrm{Br} 34$ & $2.57 \AA$ & $\mathrm{N} 34-\mathrm{S} 35$ & $1.57 \AA$ & $1.62 \AA$ & $1.62 \AA$ & $1.57 \AA$ \\
\hline $\mathrm{H} 27-\mathrm{Br} 34$ & $2.54 \AA$ & $\mathrm{S} 35-\mathrm{O} 38$ & $1.42 \AA$ & $1.46 \AA$ & $1.46 \AA$ & $1.42 \AA$ \\
\hline $\mathrm{H} 6-\mathrm{Br34}$ & $2.45 \AA$ & $\mathrm{S} 35-\mathrm{C} 39$ & $1.83 \AA$ & $1.89 \AA$ & $1.88 \AA$ & $1.83 \AA$ \\
\hline $\mathrm{C} 17-\mathrm{H} 18--\mathrm{Br}$ & $155^{\circ}$ & $\mathrm{C} 39-\mathrm{F} 44$ & $1.32 \AA$ & $1.33 \AA$ & $1.34 \AA$ & $1.32 \AA$ \\
\hline $\mathrm{C} 2-\mathrm{H} 6--\mathrm{Br}$ & $153^{\circ}$ & $\mathrm{S} 35-\mathrm{N} 34-\mathrm{S} 36$ & $125^{\circ}$ & $126^{\circ}$ & $124^{\circ}$ & $129^{\circ}$ \\
\hline $\mathrm{C} 22-\mathrm{H} 27--\mathrm{Br}$ & $156^{\circ}$ & S36-N34-S35-C39 & $92.6^{\circ}$ & $88.9^{\circ}$ & $101^{\circ}$ & $103^{\circ}$ \\
\hline & & S35-N34-S36-C40 & $92.3^{\circ}$ & $88.4^{\circ}$ & $93^{\circ}$ & $89^{\circ}$ \\
\hline & C39-S35-S36-C40 & $172^{\circ}$ & $165^{\circ}$ & $171^{\circ}$ & $161^{\circ}$ \\
\hline
\end{tabular}

Table 2. Selected bond lengths $(\AA)$, bond angles $\left({ }^{\circ}\right)$ and dihedral angles $\left({ }^{\circ}\right)$ for optimized structure of $\operatorname{PIP}{ }_{14} \mathrm{Br}$ using DFT method and $\mathrm{PIP}_{14} \mathrm{NTf}_{2}$ using DFT, MP2 and HF methods as well as its reported crystal data: 


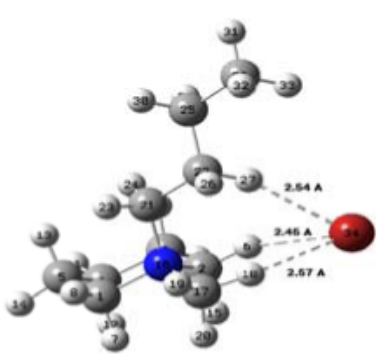

(a) $\mathrm{PIP}{ }_{14} \mathrm{Br}(\mathrm{mp}=241 \times \mathrm{C})$

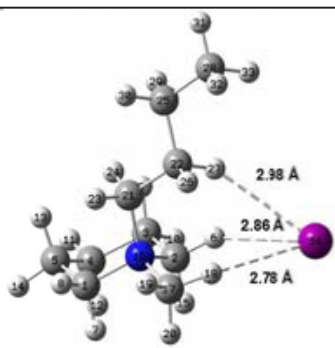

(c) PIP ${ }_{141}(\mathrm{mp}=198)$

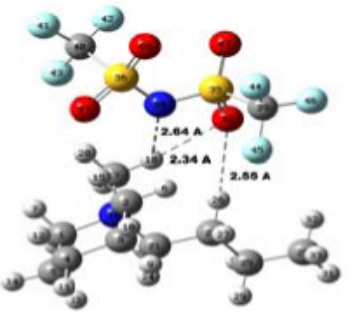

(e) $\mathrm{PIP}{ }_{14} \mathrm{NTf}_{2}(\mathrm{mp}=-25 区 \mathrm{C})$

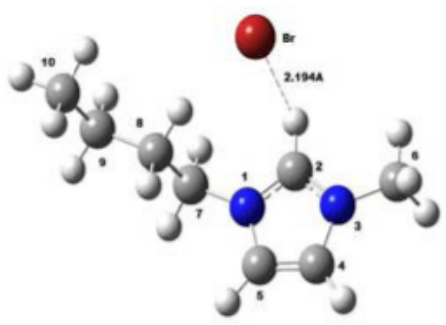

(b) $\operatorname{bmimBr}(\mathrm{mp}=79 \mathbb{} \times)$

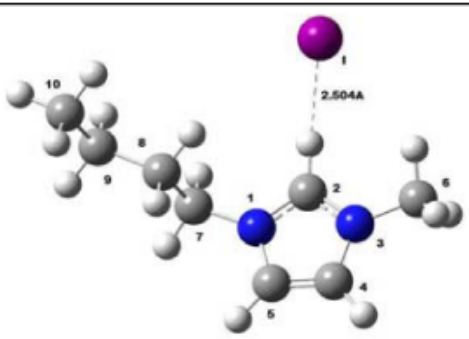

(d) bmiml $(\mathrm{mp}=-72)$

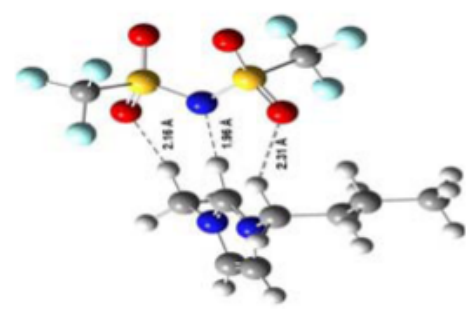

(f) bmimNTf $2(m p=-25 区 C)$

Figure 7. Optimized structure of (a) N-methyl-N-butylpiperidinium bromide ( $\mathrm{PIP}{ }_{14} \mathrm{Br}$ ) and (b)1-butyl-3-methylimidazolium bromide (bmimBr), (c) N-methyl-N-butylpiperidinium iodide ( $\left.\mathrm{PIP}_{14} \mathrm{I}\right)$, (d) 1-butyl-3-methylimidazolium iodide (bmi$\mathrm{ml}$ ), (e) N-methyl-N-butylpiperidinium bis(trifluoromethanesulfonyl)imide ( IIP $_{14} \mathrm{NTf}_{2}$ ), (f) 1-butyl-3-methylimidazolium bis(trifluoromethanesulfonyl)imide $($ bmimNTf 2$)$

\subsection{Experimental and theoretical infrared spectrum of $\mathrm{PIP}_{14} \mathrm{NTf}_{2}$}

The analysis of IR spectra also expected to bring its contribution to the general debate of the ILs intermolecular structure. Experimental Infrared (IR) spectrum for synthesized $\mathrm{PIP}_{14} \mathrm{NTf}_{2}$ has been shown in Figure 8. It has been observed that the major peaks appeared at 570, 619, 1054, 
1139, 1197, 1348, 1474, 2881 and $2966 \mathrm{~cm}^{-1}$ which are quite intense. These peaks are analysed with the help of frequency calculation using DFT and HF methods. Theoretical investigations were done to find out, which method reproduces better correlation with the experimental result. We performed vibrational frequency calculation of $\mathrm{PIP}_{14} \mathrm{NTf}_{2}$ ion pair in gaseous phase using DFT/B3LYP and HF methods. Figure 9 contains a plot of combined experimental versus theoretical vibrational frequencies using B3LYP and HF methods. It is very clear from Figure 9 that DFT/B3LYP method correlate better with the experimental results, when compared with HF method. PIP ${ }_{14} \mathrm{NTf}_{2}$ ion pair requires a scale factor of 0.966 (DFT) in higher wavenumber region (above $1500 \mathrm{~cm}^{-1}$ ) to produce the experimental vibrational frequencies. The HF method overestimates the vibrational frequencies to a greater degree than B3LYP method and requires a scale factor of 0.915 to reproduce the experimental frequencies. Similar theoretical results have been obtained for a wide range of imidazolium based ionic liquids.[26-27] The overall correlation of band positions in calculated vibrational frequencies at B3LYP level agree reasonably well with the obtained experimental frequencies. On the basis of our DFT calculation performed, experimental peaks have been assigned and are presented in Table 3. Band at 570 and $1054 \mathrm{~cm}^{-1}$ assign to be out of plane bending of $\mathrm{N}$ and $\mathrm{S}=\mathrm{O}$ symmetric stretching weakly coupled with S-N asymmetric stretching respectively. Band at 1139 and $1197 \mathrm{~cm}^{-1}$ correspond to CF stretching and C-F symmetric bending. Band at 2881 and $2966 \mathrm{~cm}^{-1}$ correspond to symmetric and asymmetric $\mathrm{C}-\mathrm{H}$ stretching in cation. The overall correlation of band positions in calculated vibrational frequencies at B3LYP level agree reasonably well with the obtained experimental frequencies. In addition, theoretically determined relative intensities are also found to be in good agreement with experimental intensity of IR absorption band.

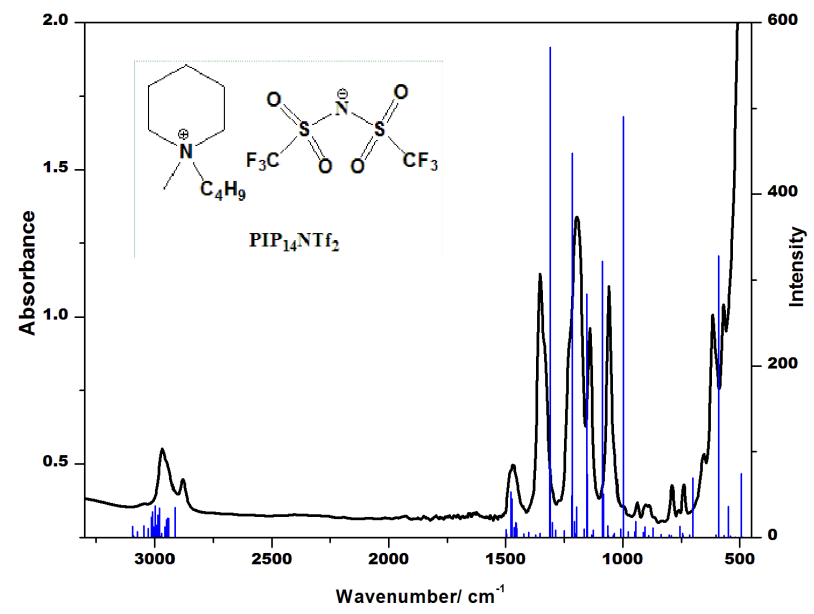

Figure 8. Infrared spectrum of neat $\mathrm{PIP}_{14} \mathrm{NTf}_{2}$ correlated with calculated vibrational bands (vertical lines). A scaling factor of 0.9664 was required to reproduce the experimental observations at higher wavenumber region. 


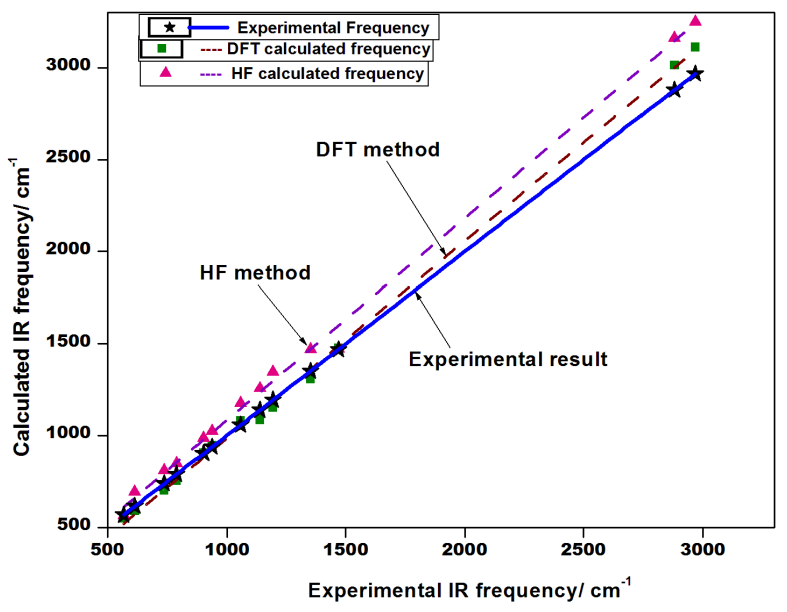

Figure 9. Correlation diagram for IR spectrum of $\mathrm{PIP}_{14} \mathrm{NTf}_{2}$; experimental versus calculated IR frequencies. (DFT and HF method). Scaling factors $=0.966$ (B3LYP) and $0.915(\mathrm{HF})$.

Vibrational frequency calculation of cation and anion was also performed independently using their optimized structure at same level of calculation to analyse the shifting of band due to presence of cation/anion interaction. Selected vibrational bands for cation, anion and its ion pair are depicted in Table 4. It has been observed from DFT calculation that due to presence of anion in ion pair, frequencies of cation are shifted to a greater extent, mainly the C-H stretching bands. Symmetric and asymmetric stretching of $\mathrm{H}-\mathrm{C} 2-\mathrm{H}$ observed at 3113 and $3196 \mathrm{~cm}^{-1}$ in $\mathrm{PIP}_{14} \mathrm{NTf}_{2}$, whereas it found to be at 3082 and $3154 \mathrm{~cm}^{-1}$ respectively for $\mathrm{PIP}_{14}{ }^{+}$ cation, showing a shifting of 31 and $41 \mathrm{~cm}^{-1}$ respectively due to presence of interaction with anion. Symmetric C-H stretching of methyl group shifted from 3087 in $\mathrm{PIP}_{14}{ }^{+}$cation to 3083 in $\mathrm{PIP}_{14} \mathrm{NTf}_{2}$ ion pair, shows an insignificant deviation of $4 \mathrm{~cm}^{-1}$. Vibrational bands arising from anion shows very less shifting due to presence of cation. This may be due to delocalization of charge on $\mathrm{NTf}_{2}^{-}$anion, whereas in cation charge is totally localized on nitrogen atom. Hence due to cation-anion interaction, cationic species shows significant shifting in their peak position. 
http://dx.doi.org/10.5772/51797

\begin{tabular}{|c|c|c|c|c|}
\hline $\begin{array}{l}\text { Wavenumber/ } \\
\mathrm{cm}^{-1} / \text { DFT (Expt.) }\end{array}$ & Intensity & $\begin{array}{l}\text { Wavenumber/ } \\
\qquad \mathrm{cm}^{-1} / \mathrm{HF}\end{array}$ & Intensity & Band assignment in PIPNTf2 \\
\hline $549(568)$ & 36 & 629 & 69 & Scissoring in $\mathrm{O}=\mathrm{S}=\mathrm{O}$ and $\mathrm{CF} 3$ \\
\hline $589(570)$ & 327 & 694 & 435 & Out of plane bending of $\mathrm{N}$ in $\mathrm{NTf}_{2}$ anion \\
\hline 701 (739) & 69 & 810 & 84 & N-S sym stretching \\
\hline $755(790)$ & 13 & 847 & 21 & C-F and N-S sym stretching \\
\hline 905 (905) & 12 & 987 & 22 & $\mathrm{~N}-\mathrm{C}(\mathrm{CH} 3)$ stretching and twisting in $\mathrm{H}-\mathrm{C}-\mathrm{H}$ \\
\hline $945(938)$ & 18 & 1025 & 20 & $\mathrm{~N}-\mathrm{C}$ stretching and rocking of $\mathrm{H}-\mathrm{C}-\mathrm{H}$ \\
\hline 997 & 490 & 1176 & 416 & S-N asym stretching and $\mathrm{S}=\mathrm{O}$ sym stretching \\
\hline $1086(1054)$ & 321 & 1257 & 565 & $\mathrm{~S}=\mathrm{O}$ sym stretching and $\mathrm{S}-\mathrm{N}$ asym stretching \\
\hline 1149 & 74 & 1341 & 272 & C-F asym stretching \\
\hline $1152(1139)$ & 283 & 1346 & 103 & C-F stretching \\
\hline $1196(1197)$ & 35 & 1379 & 338 & C-F sym bending in NTf2 (umberalla bending) \\
\hline 1213 & 447 & 1405 & 374 & $\begin{array}{l}\text { C-F asym stretching and } \mathrm{N}-\mathrm{S} \text { stretching and twisting } \\
\text { of } \mathrm{H}-\mathrm{C}-\mathrm{H}\end{array}$ \\
\hline 1309 & 571 & 1470 & 715 & $\begin{array}{c}\mathrm{S}=\mathrm{O} \text { asym stretching, Twisting of } \mathrm{H}-\mathrm{C}-\mathrm{H} \text { in PIP ring } \\
\text { and wagging of } \mathrm{H}-\mathrm{C}-\mathrm{H} \text { in } \mathrm{Bu} \text { group }\end{array}$ \\
\hline $1480(1469)$ & 10 & 1569 & 5 & $\mathrm{H}-\mathrm{C}-\mathrm{H}$ wagging and umbrella bending in $\mathrm{CH} 3$ group \\
\hline 1523 & 44 & 1653 & 77 & Scissoring of $\mathrm{H}-\mathrm{C}-\mathrm{H}$ \\
\hline $3015(2881)$ & 35 & 3162 & 43 & sym C25-H stretching in Bu group \\
\hline 3041 & 22 & 3182 & 27 & sym C-H stretching in terminal $\mathrm{CH} 3$ group \\
\hline 3083 & 34 & 3238 & 6 & sym $\mathrm{C}-\mathrm{H}$ stretching in $\mathrm{N}-\mathrm{Me}$ group and $\mathrm{C} 1-\mathrm{H}$ \\
\hline $3089(2966)$ & 26 & 3241 & 15 & sym $\mathrm{C} 1-\mathrm{H}$ and asym $\mathrm{C} 5-\mathrm{H}$ stretching in PIP ring \\
\hline 3100 & 36 & 3247 & 16 & asym $\mathrm{C} 3-\mathrm{H}$ and $\mathrm{C} 4-\mathrm{H}$ stretching in PIP ring \\
\hline 3113 & 29 & 3250 & 52 & sym $\mathrm{C} 2-\mathrm{H}$ stretching in PIP ring \\
\hline 3118 & 23 & 3255 & 46 & asym $\mathrm{C} 28-\mathrm{H}$ stretching in Bu group \\
\hline 3131 & 10 & 3292 & 14 & asym $\mathrm{C} 1-\mathrm{H}$ stretching in Pip ring \\
\hline 3151 & 13 & 3326 & 20 & asym $\mathrm{C} 21-\mathrm{H}$ stretching in Bu group \\
\hline 3196 & 11 & 3356 & 6 & asym C2-H stretching \\
\hline 3202 & 12 & 3388 & 7 & asym C-H stretching in N-Me group \\
\hline
\end{tabular}

Sym-symmetric; asym- asymmetric

Table 3. Selected IR frequencies of PIP ${ }_{14} \mathrm{NTf}_{2}$ calculated using DFT and HF methods. Experimental results are written in parentheses: 


\begin{tabular}{|c|c|c|c|c|}
\hline $\begin{array}{l}\text { Wavenumber/ } \\
\text { cm-1/ DFT }\end{array}$ & Intensity & $\begin{array}{l}\text { Wavenumber (ion } \\
\text { pair)/ cm-1/ DFT }\end{array}$ & $\begin{array}{l}\text { Deviation due to cation } \\
\text { anion interaction }(\Delta \mathbf{u})\end{array}$ & Band assignment \\
\hline \multicolumn{5}{|l|}{$\mathrm{PIP}_{14}+$ Cation } \\
\hline 3082 & 4 & 3113 & 31 & sym C2-H stretching in PIP ring \\
\hline 3087 & 9 & 3083 & 4 & $\begin{array}{l}\text { sym C-H stretching in N-Me group and } \\
\qquad \mathrm{C} 1-\mathrm{H}\end{array}$ \\
\hline 3127 & 17 & 3118 & 9 & asym C28-H stretching in Bu group \\
\hline 3154 & 5 & 3196 & 42 & Asym $\mathrm{H}-\mathrm{C} 2-\mathrm{H}$ stretching \\
\hline 3167 & 8 & 3151 & 16 & asym C21-H stretching in Bu group \\
\hline 3194 & 2 & 3202 & 8 & Asym C-H stretching in $\mathrm{N}-\mathrm{CH} 3$ \\
\hline \multicolumn{5}{|l|}{$\mathrm{NTf}_{2}$-anion } \\
\hline 700 & 8 & 701 & 1 & N-S sym stretching \\
\hline 992 & 600 & 997 & 5 & S-N asym stretching \\
\hline 1303 & 500 & 1309 & 6 & $\mathrm{~S}=\mathrm{O}$ asym stretching \\
\hline
\end{tabular}

Table 4. Selected vibrational frequencies of $\mathrm{PIP}_{14}{ }^{+}$cation, $\mathrm{NTf}_{2}{ }^{-}$anion and its ion pair

\subsection{UV-visible spectra of $\operatorname{PIP}_{14} \mathrm{NTf}_{2}$ and bmimNTf}

Since application of the ILs as media of photophysical studies depend on how transparent these substances are in the optical region, we have characterised the UV-visible absorption

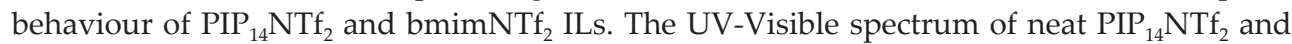
bmimNTf $\mathrm{ILs}_{2}$ is presented in Figure 10. Contrary to imidazolium based ILs, piperidinium based ILs shows wide range of transparency in UV region. bmimNTf $\mathrm{IL}_{2}$ shows non-negligible absorption in the UV region, with an absorption tail extending well into the visible region. Initially, the band of the spectrum for charcoal treated $\mathrm{PIP}_{14} \mathrm{NTf}_{2}$ appears at $258 \mathrm{~nm}$, with its absorption tail extended upto $325 \mathrm{~nm}$. But on further charcoal treatment, absorbance as well as its extended tail diminish sharply. As it is well known fact that during the process of synthesising these ILs, often colour impurity makes the resultant ILs coloured. In most of the cases improperly purified or unpurified ILs shows pale colour whereas on persistent and proper purifications, the final IL comes out to be colourless. So, to understand whether the $\mathrm{PIP}_{14} \mathrm{NTf}_{2}$ is inherently light yellow coloured or the colour is due to presence of impurity, charcoal treatment of synthesized IL was carried out repeatedly. Successive recording of 
UV-visible spectra was done after each charcoal treatment and it was observed that absorbance diminishes sharply. Hence we obtained a wide transparent window in UV-visible region for $\mathrm{PIP}_{14} \mathrm{NTf}_{2} \mathrm{IL}$. This gives us an idea that phtophysical studies or electron transfer reaction of several donor-acceptor complexes can be carried out in $\mathrm{PIP}_{14} \mathrm{NTf}_{2}$ IL whose absorption is in UV region as well. This very unique and interesting property of $\mathrm{PIP}_{14} \mathrm{NTf}_{2} \mathrm{IL}$ revealed the extensive study of piperidinium based ILs in fluorescence study also.

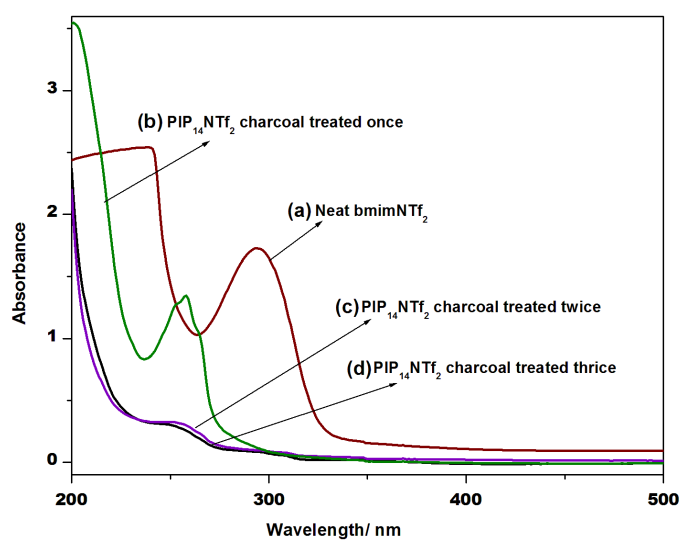

Figure 10. UV-visible spectrum of $\mathrm{PIP}_{14} \mathrm{NTf}_{2}$ compared with that of bmimNTf

\section{Conclusion}

Synthesis of several imidazolium and piperidinium based ILs and their physical properties are reported. Melting point of piperidinium based ILs found to be higher than its imdazolium based ILs, anion being identical. This was explained by DFT calculation which clearly shows the higher number of hydrogen bonding present in piperidinium based ILs than imidazolium based ILs. Whereas, in bmimBr or bmimI, no H- bonding was observed between anion and alkyl chain, while two H-bonding with alkyl chain along with one H-bonding with hydrogen of piperidine ring was observed. Hence this higher number of H-bonding present in $\mathrm{PIP}_{14} \mathrm{Br}$ and $\mathrm{PIP}_{14} \mathrm{I}$ led to its higher melting point than its corresponding analogues ILs, bmimBr or bmimI respectively. Viscosity of ILs is also controlled by number of hydrogen bonding between cation and anion, as well as vander Waal interactions present in it. Though the viscosity of $\mathrm{PIP}_{14} \mathrm{NTf}_{2}$ is higher than that of bmimNTf trochemical window for the former makes it more useful in electrochemical applications. DFT calculation reproduces the experimental IR spectrum very well as compared to HF method. Finally, piperidinium based ILs shows wide range of optical transparency making it markedly superior for photophysical studies (e.g. electron transfer reaction) in it. 


\section{Acknowledgement}

Financial assistance from CSIR, India (01(2210)/08/EMR-II) and DST, India (SR/FTP/ CS-70/2006) are gratefully acknowledged. Authors also thank the department of Chemistry, Banaras Hindu University for infrastructural instrumentation facilities. Hyderabad Central University, Hyderabad is gratefully acknowledged for computational facility (CMSD) for providing computational facility. MLS thanks University Grant Commission, New Delhi for providing fellowship.

\section{Author details}

Madhulata Shukla and Satyen Saha

Department of Chemistry, Faculty of Science, Banaras Hindu University, Varanasi, India

\section{References}

[1] Wishart J F. (2009). Energy applications of ionic liquids. Energy Environ. Sci., , 2, 956-961.

[2] Plechkova N V, Seddon K R. (2008). Applications of ionic liquids in the chemical industry. Chem. Soc. Rev., , 37, 123-150.

[3] Metlen M S A, Rogers R D. (2007). The second evolution of ionic liquids: from solvents and separations to advanced materials: energetic examples from the ionic liquid cookbook. Acc. Chem. Res., , 40, 1182-1192.

[4] Fei, Z. F., Geldbach, T. J., Zhao, D. B., \& Dyson, P. J. (2006). From dysfunction to bisfunction: on the design and applications of functionalised ionic liquids. Chem. Eur. J., , 12, 2123-2130.

[5] Wasserscheid, P., \& Keim, W. (2000). Ionic Liquids- New solutions for transition metal catalysis. Angew. Chem., Int. Ed., , 39, 3772-3789.

[6] Welton, T. (1999). Room-temperature ionic liquids. Solvents for synthesis and catalysis. Chem. Rev., , 99, 2071-2083.

[7] Wilkes J S.(2002). A short history of ionic liquids-from molten salts to neoteric solvents Green Chem., , 4, 73-80.

[8] Castner Jr, E. W., Margulis, C. J., Maroncelli, M., \& Wishart, J. F. (2011). Ionic Liquids: Structure and Photochemical Reactions, Annu. Rev. Phys. Chem., , 62, 85-105. 
[9] Dupont, J., Suarez, P. A. Z., Umpierre, A. P., \& de Souza, R. F. (2000). Pd(II)-dissolved in ionic liquids: a recyclable catalytic system for the selective biphasic hydrogenation of dienes to monoenes. J. Braz. Chem. Soc., , 11, 293-297.

[10] Xu L J, Chen W P, Xiao J L,(2000). Heck Reaction in Ionic Liquids and the in Situ Identification of N-Heterocyclic Carbene Complexes of Palladium. Organometallics, , $19,1123-1127$.

[11] Carmichael A J, Earle M J, Holbrey J D, McCormac P B, Seddon K R. (1999). The Heck Reaction in Ionic Liquids: A Multiphasic Catalyst System. Org. Lett., , 1-997.

[12] Brown, R. A., Pollet, P., Mc Koon, E., Eckert, C. A., Liotta, C. L., \& Jessop, P. G. (2001). Asymmetric Hydrogenation and Catalyst Recycling Using Ionic Liquid and Supercritical Carbon Dioxide. J. Am. Chem. Soc., , 123-1254.

[13] Olivier, H. (1999). Recent developments in the use of non-aqueous ionic liquids for two-phase catalysis. J. Mol. Catal. A: Chem., , 146-285.

[14] Huddleston J G, Willauer H D, Swatloski R P, Visser A E, Rogers R D.(1998). Room temperature ionic liquids as novel media for 'clean' liquid-liquid extraction. Chem. Commun., , 1765-1766.

[15] Song C E, Roh E J. (2000). Practical method to recycle a chiral (salen)Mn epoxidation catalyst by using an ionic liquid. Chem. Commun., , 837-838.

[16] Anderson J L, Armstrong D W. (2003). High-Stability Ionic Liquids. A New Class of Stationary Phases for Gas Chromatography. Anal. Chem., , 75-4851.

[17] Armstrong D W, He L F, Liu Y S, (1999). Examination of Ionic Liquids and Their Interaction with Molecules, When Used as Stationary Phases in Gas Chromatography. Anal. Chem., , 71, 3873-3876.

[18] Bhatt, A. I., May, I., Volkovich, V. A., Hetherington, M. E., Lewin, B., Thied, R. C., \& Ertok, N. (2002). Group 15 quaternary alkyl bistriflimides: ionic liquids with potential application in electropositive metal deposition and as supporting electrolytes. J. Chem. Soc. Dalton Trans., , 24, 4532-4534.

[19] Suarez, P. A. Z., Einloft, S., Dukkius, J. L., de Souza, R. F., \& Dupont, J. (1998). Synthesis and physical-chemical properties of ionic liquids based on 1- n-butyl-3-methylimidazolium cation J. Chim. Phys., , 95, 1626-1639.

[20] Holbrey J D, Seddon K R. (1999). The phase behaviour of alkyl-3-methylimidazolium tetrafluoroborates; ionic liquids and ionic liquid crystals, J. Chem. Soc., Dalton Trans., 2133-2139., 1.

[21] Triolo, A., Russina, O., Bleif, H. J., \& Cola, E. D. (2007). Nanoscale Segregation in Room Temperature Ionic Liquids. J. Phys. Chem. B, , 111, 4641-4644.

[22] Ozawa, R., Hayashi, S., Saha, S., Kobayashi, A., \& Hamaguchi, H. (2003). Rotational Isomerism and Structure of the 1-Butyl-3-methylimidazolium Cation in the Ionic Liquid State. Chem. Lett., , 32, 948-949. 
[23] Shukla, M., Srivastava, N., \& Saha, S. (2010). Theoretical and spectroscopic studies of 1-butyl-3-methylimidazolium iodide room temperature ionic liquid: Its differences with chloride and bromide derivatives, J. Mol. Struct., , , 975, 349-356.

[24] Shukla, M., Srivastava, N., \& Saha, S. (2011). Interactions and Transitions in Imidazolium Cation Based Ionic Liquids in Ionic Liquids-classes and properties, , 150-170.

[25] Tsuzuki, S., Katoh, R., \& Mikami, M. (2008). Analysis of interactions between 1-butyl-3-methylimidazolium cation and halide anions (Cl-, Br- and I-) by ab initio calculations: anion size effects on preferential locations of anions Mol. Phys., , 106, 1621-1629.

[26] Krossing, I., Slattery, J. M., Daguenet, C., Dyson, P. J., Oleinikova, A., \& Weinga, H. (2006). Why Are Ionic Liquids Liquid? A Simple Explanation Based on Lattice and Solvation Energies, J. Am. Chem. Soc., , 128, 13427-13434.

[27] Talaty, E. R., Raja, S., Storhaug, V. J., Dolle, A., \& Carper, W. R. (2004). Raman and Infrared Spectra and ab Initio Calculations of C2-4MIM Imidazolium Hexafluorophosphate Ionic Liquids. J. Phys. Chem. B, 108, 13177-13184.

[28] Fumino, K., Wulf, A., \& Ludwig, R. (2009). The potential role of hydrogen bonding in aprotic and protic ionic liquids. Phys. Chem. Chem. Phys., 11, 8790-8794.

[29] Tsuda, T., Kondo, K., Tomioka, T., Takahashi, Y., Matsumoto, H., Kuwabata, S., \& Hussey, C. L. (2011). Design, Synthesis, and Electrochemistry of Room-Temperature Ionic Liquids Functionalized with Propylene Carbonate, Angew. Chem. Int. Ed., 50, 1310-1313.

[30] Lava, K., Binnemans, K., \& Cardinaels, T. (2009). Piperidinium, Piperazinium and Morpholinium Ionic Liquid Crystals, J. Phys. Chem. B , 113, 9506-9511.

[31] Egashira, M., Okada, S., Yamaki, J., Yoshimoto, N., \& Morita, M. (2005). Effect of small cation addition on the conductivity of quaternary ammonium ionic liquids Electrochimica Acta, 50, 3708-3712.

[32] Triolo, A., Russina, O., Fazio, B., Battista, G., Carewska, A. M., \& Passerini, S. (2009). Nanoscale organization in piperidinium-based room temperature ionic liquids J. Chem. Phys. 130, 164521 (1-6).

[33] Salminen, J., Papaiconomou, N., Kumara, R. A., Lee, J. M., Kerr, J., Newmana, J., \& Prausnitz, J. M. (2007). Physicochemical properties and toxicities of hydrophobic piperidinium and pyrrolidinium ionic liquids" Fluid Phase Equilibria , 261, 421-426.

[34] Yuan, L. X., Feng, J. K., Ai, X. P., Cao, Y. L., Chen, S. L., \& Yang, H. X. (2006). Improved dischargeability and reversibility of sulfur cathode. Electrochem. Comm., 8, 610-614.

[35] Matsumoto, K., \& Hagiwara, R. (2009). A New Series of Ionic Liquids Based on the Difluorophosphate Anion. Inorg. Chem., 48, 7350-7358. 
[36] Rao, C. J., Krishnan, R. V., Venkatesan, K. A., Nagarajan, K., \& Srinivasan, T. G. (2009). Thermochemical properties of some bis(trifluoromethyl sulfonyl)imide based room temperature ionic liquids. J. Therm. Anal. Calorim., 97, 937-943.

[37] Lewandowski, A., \& Widerska, A. S. (2004). New composite solid electrolytes based on a polymer and ionic liquids. Solid State Ionics, 169, 21-24.

[38] Sakaebe, H., \& Matsumoto, H. (2003). N-Methyl-N-propylpiperidinium bis(trifluoromethanesulfonyl)imide (novel electrolyte base for Li battery. Electrochem. Comm. 5, 594-598., 13.

[39] Fernanda, F., Bazito, C., Kawano, Y., \& Torresi, R. M. (2007). Synthesis and characterization of two ionic liquids with emphasis on their chemical stability towards metallic lithium. Electrochimica Acta , 52, 6427-6437.

[40] Zhou, Z. B., Matsumoto, H., \& Tatsumi, K. (2006). Cyclic Quaternary Ammonium Ionic Liquids with Perfluoroalkyltrifluoroborates: Synthesis, Characterization, and Properties. Chem. Eur. J., 12, 2196-2212.

[41] Cho T Y, Yoon S G, Sekhon S S, Han C H(2011). Effect of Ionic Liquids with Different Cations in I-/I3- Redox Electrolyte on the Performance of Dye-sensitized Solar Cells Bull. Korean Chem. Soc., , 32, 2058-2062.

[42] Reichert, W. M., Henderson, W. A., Trulove, P. C., Urban, J. J., \& De Long, H. C. (2010). Effects of Crystal Packing on the Thermal Behavior of $N_{,} \mathrm{N}^{\prime}$-alkylpiperidinium and N,N'-alkylmorpholinium Iodide Salts. ECS Transactions , 33, 667-677.

[43] Haddad, B., Villemin, D., \& Belarbi, E. (2012). Synthesis, Differential Scanning Calorimetry (DSC) and Dielectric Relaxation Spectroscopy (DRS) Studies of N-methyl-N NpropylpiperidiniumBis(trifluoromethylsulfonyl)imide J. Mater. Environ. Sci., , 3, 312-319.

[44] Xu, K. (2004). Nonaqueous Liquid Electrolytes for Lithium-Based Rechargeable Batteries. Chem. Rev., , 104, 4303-4417.

[45] Nakagawa, N., Izuchi, S., Kuwana, K., Nukuda, T., \& Aihara, Y. (2003). Liquid and Polymer Gel Electrolytes for Lithium Batteries Composed of Room-Temperature Molten Salt Doped by Lithium Salt J. Electrochem. Soc., 150, AA700;, 695.

[46] Garcia, B., Lavallee, S., Perron, G., Michot, C., \& Armand, M. (2004). Room temperature molten salts as lithium battery electrolyte, Electrochim. Acta, , 49, 4583-4588.

[47] Matsumoto, H., Sakaebe, H., \& Tatsumi, K. (2005). Preparation of room temperature ionic liquids based on aliphatic onium cations and asymmetric amide anions and their electrochemical properties as a lithium battery electrolyte J. Power Sources, , 146, 45-50.

[48] Sakaebe, H., \& Matsumoto, H. (2003). N-Methyl-N-propylpiperidinium bis(trifluoromethanesulfonyl)imide (novel electrolyte base for Li battery Electrochem. Commun., 5, 594-598., 13. 
[49] Shin, J. H., Henderson, W. A., \& Passerini, S. (2003). Ionic liquids to the rescue: Overcoming the ionic conductivity limitations of polymer electrolytes Electrochem. Commun., , 5, 1016-1020.

[50] Sato, T., Maruo, T., Marukane, S., \& Takagi, K. (2004). Ionic liquids containing carbonate solvent as electrolytes for lithium ion cells J. Power Sources , 138, 253-261.

[51] Howlett P C, MacFarlane D R, Hollenkamp A F,(2004). High Lithium Metal Cycling Efficiency in a Room-Temperature Ionic Liquid. Electrochem. Solid-State Lett., 7, AA101., 97.

[52] Matsumoto, H., Yanagida, M., Tanimoto, K., Nomura, M., Kitagawa, Y., \& Miyazaki, Y. (2000). Highly Conductive Room Temperature Molten Salts Based on Small Trimethylalkylammonium Cations and Bis(trifluoromethylsulfonyl)imide Chem. Lett., , 29, 922-923.

[53] Baranchugov, V., Markevich, E., Pollak, E., Salitra, G., \& Aurbach, D. (2007). Amorphous silicon thin films as a high capacity anodes for Li-ion batteries in ionic liquid electrolytes, Amorphous silicon thin films as a high capacity anodes for Li-ion batteries in ionic liquid electrolytes Electrochem. Commun., , 9, 796-800.

[54] Yuan, L. X., Feng, J. K., Ai, X. P., Cao, Y. L., Chen, S. L., \& Yang, H. X. (2006). Improved dischargeability and reversibility of sulfur cathode in a novel ionic liquid electrolyte, Electrochem. Commun., , 8, 610-614.

[55] Fuller, J., Breda, A. C., \& Carlin, R. T. (1997). Ionic liquid-polymer gel electrolytes, J. Electrochem. Soc., 144, L667.

[56] Lee, J. M., Ruckes, S., \& Prausnitz, J. M. (2008). Solvent polarities and Kamletâ^’Taft parameters for ionic liquids containing a pyridinium cation, J. Phys. Chem. B, , 112-1473.

[57] Hinckley, G., Mozhaev, V. V., Budde, C., \& Khmelnitsky, Y. L. (2002). Oxidative enzymes possess catalytic activity in systems with ionic liquids, Biotechnol. Lett., , 24, 2083-2087.

[58] Peter, W., \& Wilhelm, K. (2000). Ionic liquids-new ldquoSolutionsrdquo for transition metal catalysis, Angew. Chem., , 39-3772.

[59] Reiter, J., \& Nadherna, M. (2012). N-Allyl-N-methylpiperidinium bis(trifluoromethanesulfonyl)imide-A film forming ionic liquid for graphite anode of Li-ion batteries, Electrochimica Acta, , 71, 22-26.

[60] Holbrey, J. D., Reichert, W. M., Nieuwenhyuzen, M., Johnston, S., Seddon, K. R., \& Rogers, R. D. (2003). Crystal polymorphism in butyl-3-methylimidazolium halides: supporting ionic liquid formation by inhibition of crystallization, Chem. Commun., 1636-1637., 1.

[61] Anthony, J. L., Brennecke, J. F., Holbrey, J. D., Maginn, E. J., Mantz, R. A., Rogers, R. D., Trulove, P. C., Visser, A. E., \& Welton, T. (2003). Physicochemiocal properties of 
ionic liquids. In Wassercheid P \& Welton T (Eds) Ionic Liquids in Synthesis, WileyWCH, Weinheim: , 41-126.

[62] Mac, Farlane. D. R., Meakin, P., Sun, J., Amini, N., \& Forsyth, M. (1999). Pyrrolidinium Imides:A New Family of Molten Salts and Conductive Plastic Crystal Phases, J. Phys. Chem. B, , 103, 4164-4170.

[63] Zhou, Z. B., Matsumoto, H., \& Tatsumi, K. (2004). Low-Melting, Low-Viscous, Hydrophobic Ionic Liquids: 1-Alkyl(Alkyl Ether)-3-methylimidazolium Perfluoroalkyltrifluoroborate, Chem. Eur. J., , 10, 6581-6591.

[64] Lide DR. (2003). CRC Handbook of chemistry and physics, 84 edition, CRC press, Boca Raton, New York.

[65] Stenzel, O., Raubenheimer, H. G., \& Esterhuysen, C. (2002). Biphasic hydroformulation in new molten salts- analogies and differences to organic solvents. J. Chem. Soc. Dalton Trans, , 1132-1138.

[66] Huddleston J G, Visser A E, Reichert W M, Willauer H D, Broker G A, Rogers R. D. (2001). Characterization and comparision of hydrophilic and hydropbobic room temperature ionic liquids incorporating the imidazolium cation, Green Chem., , 3, 156-164.

[67] Alavi, S., \& Thompson, D. L. (2005). Molecular dynamics studies of melting and some liquid-state properties of ethyl-3-methylimidazolium hexafluorophosphate [emim][PF6], J. Chem. Phys., 122, 154704., 1.

[68] Sun, J., Forsyth, M., \& Mac, Farlane. D. R. (1998). Room-Temperature Molten Salts Based on the Quaternary Ammonium Ion. J. Phys. Chem. B, , 102, 8858-8864.

[69] Wang, J., Wang, H., Zhang, S., Zhang, H., \& Zhao, J. Y. (2007). Conductivities, Volumes, Fluorescence, and Aggregation Behavior of Ionic Liquids [C4mim][BF4] and [Cnmim]Br $(\mathrm{n}=4,6,8,10,12)$ in Aqueous Solutions J. Phys. Chem. B, , 111, 6181-6188.

[70] Turner E A, Pye C C, Singer R D.(2003). Use of ab Initio calculation towards the rational design of room temperature ionic liquids, J. Phys. Chem. A, , 107, 2277-2288.

[71] Furlani, M., Albinsson, I., Mellander, B. E., Appetecchi, G. B., \& Passerini, S. (2011). Annealing protocols for pyrrolidinium bis(trifluoromethylsulfonyl)imide type ionic liquids, Electrochemica Acta , 57, 220-227.

[72] Bonhote, P., Dias, A. P., Papageogiou, N., Kalyanasundaram, K., \& Gratzel, M. (1996). Hydrophobic, Highly Conductive Ambient-Temperature Molten Salts, Inorg. Chem., , 35, 1168-1178.

[73] Rogers R D, Visser A E, Swatloski R P, Hartman D H.(2000). in Metal Ion Separations Beyond: Integrating Novel Chemistry with Processing, ed.

[74] Liddell K C, Chaiko D J.(1999). The Minerals, Metals and Materials Society, Warrendale, PA, , 139-147. 
[75] Belhocine, T., Forsyth, S. A., Gunaratne, H. Q. N., Nieuwenhuyzen, M., Puga, A. V., Seddon, K. R., Srinivasan, G., \& Whiston, K. (2011). New ionic liquids from azepane and 3-methylpiperidine exhibiting wide electrochemical windows, Green Chem, , 13, 59-63.

[76] Becke A D.(1988). Density-functional exchange-energy approximation with correct asymptotic behaviour, Phys. Rev. A, , 38, 3098-3100.

[77] Lee, C., Yang, W., \& Parr, R. G. (1988). Development of the Colle-Salvetti correlationenergy formula into a functional of the electron density, Phys. Rev. B, , 37, 785-789.

[78] Frisch, M. J., et al. (2004). Gaussian 03, Revision C.02, Gaussian, Inc., Wallingford, CT.

[79] Fujii, K., Fujimori, T., Takamuku, T., Kanzaki, R., Umebayashi, Y., \& Ishiguro, S. (2006). Conformational Equilibrium of Bis(trifluoromethanesulfonyl) Imide Anion of a Room-Temperature Irequency onic Liquid: Raman Spectroscopic Study and DFT Calculations J. Phys. Chem. B, , 110(16), 8179-8183. 